\title{
Predictive Factors of Rapid Cognitive Decline in Patients with Alzheimer Disease
}

\author{
Coralie Barbe $^{a, b} \quad$ Isabella Morrone ${ }^{c} \quad$ J.L. Novella ${ }^{a, c} \quad$ Moustapha Draméa, \\ b
}

Aurore Wolak-Thierry ${ }^{a, b} \quad$ Jean-Pierre Aquinod Joël Ankrie

Damien Jolly ${ }^{a}$ b Rachid Mahmoudia, $c$

\begin{abstract}
a Faculty of Medicine, EA 3797, University of Reims Champagne-Ardenne, Reims, France; ${ }^{b}$ Department of Research and Public Health, Reims University Hospital, Reims, France; 'Department of Geriatrics and Internal Medicine, Reims University Hospital, Reims, France; ${ }^{d}$ Clinique de la Porte Verte, Versailles, France; ${ }^{e}$ Centre of Gerontology, Public Assistance, Hospitals of Paris, Paris Cedex, France
\end{abstract}

\section{Keywords}

Alzheimer disease $\cdot$ Health-related quality of life $\cdot$ Rapid cognitive decline $\cdot$ Risk factors

\section{Abstract}

Aim: To determine predictive factors associated with rapid cognitive decline (RCD) in elderly patients suffering from Alzheimer disease (AD). Methods: Patients suffering from mild to moderate $A D$ were included. RCD was defined as the loss of at least 3 points on the MiniMental State Examination (MMSE) over 12 months. Factors associated with RCD were identified by logistic regression. Results: Among 123 patients included, 61 were followed up until 12 months. RCD occurred in $46 \%$ of patients $(n=28)$. Polymedication $(p<0.0001)$, the fact that the caregiver was the child or spouse of the patient $(p<0.0001)$ and autonomy for washing $(p<0.0001)$ were protective factors against RCD, while the presence of caregiver burden $(p<0.0001)$ was shown to be a risk factor for RCD. Conclusion: Early detection of the RCD risk in $A D$ patients could make it possible to anticipate the patient's medical needs and adjust the care plan for caregiver burden. 


\section{Introduction}

Alzheimer disease (AD) is characterized by progressive cognitive decline. However, the speed of this decline varies widely between individuals [1-3]. Cognitive decline in patients with AD can range from a loss of 2.7 to 4.5 points per year on the Mini-Mental State Examination (MMSE) [2]. Rapid cognitive decline (RCD) is defined as a deterioration of cognitive functions, as measured by a specific instrument for dementia, greater than the expected average decline [4]. Several studies have shown RCD to be an unfavourable prognostic factor, with consistently accelerated cognitive decline, loss of autonomy, and increased rates of death or institutionalization [5-9].

A major challenge in the management of $\mathrm{AD}$ is the implementation of a follow-up programme to optimally accompany patients and their families over the course of the disease. Anticipating states of crisis, whether of social, psychological or somatic origin, is a key element in providing assistance to patients and their caregivers. In this context, it is necessary to be able to identify at an early stage patients with RCD, since they require closer follow-up in order to optimize personalized care solutions.

Several studies have sought to identify risk factors associated with RCD. These reports have identified early onset of disease (before 65 [10] or 70 [11] years of age), a high level of education [12-16], malnutrition [9, 16, 17], and the presence of behavioural disorders [12, 18-20] as being associated with RCD.

Numerous studies have shown that health-related quality of life (HRQoL) decreases with increasing morbidity $[21,22]$, and a few studies have been conducted to validate HRQoL as a predictor of outcomes. In particular, HRQoL has been shown to predict hospitalization and mortality in patients with obstructive lung diseases [23], mortality in patients with advanced chronic liver disease [24], and hospitalization and death within 1 year in patients in primary care ambulatory clinics [25]. Furthermore, Dominick et al. [26] demonstrated that, among older adults, HRQoL was associated with health care utilization and mortality.

The aim of this study was to determine predictive factors associated with RCD in elderly patients suffering from AD.

\section{Methods}

\section{Patients and Design}

A multicentre, longitudinal study, repeated at 1 year's interval, was carried out in 7 hospitals (6 French hospitals and 1 French-speaking hospital in Switzerland). Patients were recruited from memory consultations or geriatric medicine units. To be eligible for inclusion, patients had to be aged 65 or more, have French as their native language, suffer from dementia according to the Diagnostic and Statistical Manual of Mental Disorders, 4th edition, Text Revision (DSM-IV-TR) [27] and the National Institute of Neurological and Communicative Disorders and Stroke (NINCDS) and the Alzheimer's Disease and Related Disorders Association (ADRDA) criteria [28], and have an MMSE score of 10 or more, corresponding to mild to moderate dementia $[29,30]$. This analysis corresponds to an ancillary study in which only AD patients were considered.

The protocol study was approved by the Institutional Review Board of the Reims University Hospital, France. This non-interventional study did not in any way change routine care of the patients included. A double informed consent form was signed, by both the patient and their main caregiver. Patients could withdraw from the study on request, without their withdrawal in any way affecting their management. 


\section{Data Collected}

The MMSE score was recorded at the time of inclusion and at 12 months of follow-up. RCD was defined as a loss of at least 3 points on the MMSE between inclusion and the 12-month follow-up visit [31].

Socio-demographic variables regarding the patient (age, sex, place of residence, level of education) and regarding the main caregiver (age, sex, relationship to the patient) were also recorded at patient inclusion. The presence of formal help (home nursing, home help for housework, delivery of meals, and attendance at a day care centre) was assessed using the Resource Utilization in Dementia questionnaire [32]. The existence of caregiver burden was assessed using Zarit's 22-item scale [33], which gives an overall score ranging from 0 to 88, where a score $\geq 21$ represents the presence of a caregiver burden.

Clinical evaluation was performed at inclusion. The International Classification of Diseases (ICD-10) adapted version of the Charlson index [34] was used to quantify the severity of comorbidities. The number of medications taken by the patient was also noted. Polymedication was defined as 4 or more medications per day [16]. Nutritional status was evaluated by calculating the body mass index. Malnutrition was defined as a body mass index $<21$ [35].

The Neuropsychiatric Inventory [36] was used to assess the presence of behavioural disorders. This 12-item scale gives a global score of up to 96 , which is calculated as the sum of the scores for severity (out of 36 points) and distress caused by the symptoms (out of 60 points). A high score reflects more severe or more distressing symptoms. In addition to the overall score, the specific presence of each type of behavioural disorder was investigated.

The Cornell score for depression [37], comprising 19 items in 6 scales, was used to evaluate depression among participating patients, with a score of 10 or more indicating the presence of severe depression.

Two scales were used to evaluate the level of patient dependence, namely Katz's Activities of Daily Living comprising 6 items (bathing, dressing, transferring, using the toilet, eating, and continence) [38] and Lawton's Instrumental Activities of Daily Living as adapted by the PAQUID study (Personnes Agées QUID study) to 4 items (ability to use the telephone, do the shopping, use public transport, and take responsibility for own medication) [39].

Patient HRQoL was evaluated using the Dementia Quality of Life (DQoL) instrument [40]. This questionnaire comprises 29 items in 5 domains. The "self-esteem" domain comprises 4 items, and corresponds - for the subject - to having felt confident and/or satisfied with themselves, having felt they accomplished something, or felt capable of making their own decisions. The "positive affect/humour" domain comprises 6 items (having felt happy, cheerful, content, found something that made them laugh, felt confident in the future, laughed, and joked with others). The "negative affect" domain comprises 11 items measuring how often the subject felt afraid, lonely, frustrated, embarrassed, angry, worried, depressed, nervous, sad, irritated, or anxious. The "feelings of belonging" domain comprises 3 items that evaluate how often the subjects felt useful, felt people liked them, or felt lovable. Lastly, the "sense of aesthetics" domain includes 5 items that assess the extent to which the subject derived pleasure from sensory awareness, appreciation of beauty, such as enjoyment listening to music, listening to the sounds of nature, watching animals or birds, looking at colourful things, or watching the clouds or sky. Each domain is scored from 0 to 5 , and a higher score indicates better HRQoL, except for the "negative affect" domain, where a higher score corresponds to a lower HRQoL.

\section{Statistical Analysis}

Firstly, descriptive analysis was performed. Quantitative variables are described as mean \pm standard deviation and qualitative variables as number and percentage. By univariate analysis, comparison between patients with RCD and those without was performed by the 
Wilcoxon, $\chi^{2}$ or Fisher exact tests, as appropriate. By multivariate analysis, logistic regression was performed using stepwise selection, and entry and exit thresholds set at 0.20 . All variables with a $p$ value $<0.20$ by univariate analysis were included in the multivariate analysis. As the number of events was low, the Jackknife method [41] was applied to calculate $95 \%$ confidence intervals. With the Jackknife method, each sample is singled out one by one to estimate the standard error of the $\beta$ coefficient by the rest of the samples in the dataset. Therefore, the average standard error thus obtained is more accurate and reduces the gap between the two 95\% confidence interval limits. The Wald test was used to estimate $p$ values related to the Jackknife method. A $p$ value $<0.05$ was considered statistically significant. All analyses were performed using SAS version 9.3 (SAS Inc., Cary, NC, USA).

\section{Results}

A total of 123 patients with AD were included in this study. Sixty-one patients (49.6\%) were followed up until 12 months and were included in this analysis. Anxiety (52 vs. 72\%; $p=0.006$ ), polymedication ( 36 vs. $67 \% ; p=0.0007$ ), and delusions ( 10 vs. $29 \% ; p=0.006$ ) were less present in included patients compared to excluded patients.

The baseline characteristics of the included population are presented in Table 1. Average age was $81.7 \pm 6.6$ years. The majority were women $(n=38,62.3 \%)$. Thirty patients $(49.2 \%)$ had mild dementia and 31 patients (50.8\%) moderate dementia. During the 12 months of follow-up period, 28 patients (45.9\%) experienced RCD.

The results of the univariate analysis comparing patients with RCD to those without are presented in Table 1.

Multivariate analysis identified polymedication $(p<0.0001)$, the fact that the caregiver was the child or spouse of the patient $(p<0.0001)$, and autonomy for washing $(p<0.0001)$ as protective factors against RCD, while the presence of caregiver burden was shown to be a risk factor for RCD $(p<0.0001)$ (Table 2$)$. The subscale of the DQoL included in the multivariate model (positive affects/humour) was not retained in the final model. Thus, after univariate and multivariate analysis, none of the 5 subscales of the DQoL was found to be associated with occurrence of RCD.

\section{Discussion}

In this study, we found that the presence of an immediate family member as primary caregiver had a protective effect against RCD. The spouse or adult children of the patient were considered as immediately family caregivers, while formal helpers (nurses or nurses' aides) or other relatives (e.g. siblings or in-laws) were considered as non-immediate family caregivers. The protective effect observed with immediate family members could be due to them being present more often, leading to greater stimulation of the patient. Indeed, patients suffering from $\mathrm{AD}$ need to be stimulated throughout the day, at several levels, in response to various needs (autonomy, social activities, emotions, leisure activities), and respecting the patients' choices in terms of clothing, food, favourite places to go, etc. This greater presence of an immediate family caregiver corresponds to the model of caregiving obligation described by Rossi and Rossi [42], whereby the family members with closest kinship (i.e. adult children) perceive the greatest sense of responsibility towards the patient, and thus, accord a greater deal of attention to the patient's well-being.

Autonomy in matters of personal hygiene was also found to be a protective factor against RCD in our study. Indeed, washing is a vital activity involving the patient's intimacy. The 
Barbe et al.: Predictive Factors of Rapid Cognitive Decline in Patients with Alzheimer Disease

Table 1. Baseline characteristics of the 61 patients included in the study and their main caregivers, and univariate comparison of patients with versus without rapid cognitive decline at 12 months

\begin{tabular}{|c|c|c|c|c|}
\hline & Overall $(n=61)$ a & $\operatorname{RCD}(n=28) \mathrm{a}$ & No $\operatorname{RCD}(n=33) \mathrm{a}$ & $p$ \\
\hline \multicolumn{5}{|l|}{ Patients } \\
\hline Ageb & $81.7 \pm 6.6$ & $81.4 \pm 6.0$ & $81.9 \pm 7.1$ & 0.85 \\
\hline Male sex & $23(37.7)$ & $11(39.3)$ & $12(36.4)$ & 0.81 \\
\hline High school diploma or higher education & $19(31.7)$ & $11(40.7)$ & $8(24.2)$ & 0.17 \\
\hline Home nurse & $17(28.3)$ & $7(25.0)$ & $10(31.2)$ & 0.59 \\
\hline Home help for housework & $33(54.1)$ & $13(46.4)$ & $20(60.6)$ & 0.27 \\
\hline Home delivery of meals & $14(22.9)$ & $6(21.4)$ & $8(24.2)$ & 0.79 \\
\hline Attending day care centre & $13(21.7)$ & $9(32.1)$ & $4(12.5)$ & 0.06 \\
\hline Presence of malnutritionc & 9 (15.2) & $3(11.5)$ & $6(18.2)$ & 0.72 \\
\hline Charlson indexb & $1.5 \pm 1.2$ & $1.5 \pm 1.4$ & $1.4 \pm 1.1$ & 0.88 \\
\hline Polymedicationb, d & $21(35.6)$ & $6(23.0)$ & $15(45.4)$ & 0.07 \\
\hline MMSE scoreb & $21.0 \pm 4.7$ & $20.0 \pm 4.7$ & $21.8 \pm 4.5$ & 0.11 \\
\hline NPI: global scoreb & $11.9 \pm 10.7$ & $13.0 \pm 9.6$ & $11.0 \pm 11.7$ & 0.11 \\
\hline \multicolumn{5}{|l|}{ NPI subscales: } \\
\hline Delusions & $6(9.8)$ & $3(10.7)$ & $3(9.1)$ & 0.83 \\
\hline Hallucinations & $1(1.7)$ & $1(3.7)$ & $0(0.0)$ & 0.45 \\
\hline Agitation/aggression & $28(45.9)$ & $15(53.6)$ & $13(39.4)$ & 0.27 \\
\hline Depressed mood & $2(3.8)$ & $1(4.2)$ & $1(3.6)$ & 0.91 \\
\hline Anxiety & $32(52.5)$ & $14(50.0)$ & $18(54.5)$ & 0.72 \\
\hline Euphoria & $18(29.5)$ & $9(32.1)$ & $9(27.3)$ & 0.68 \\
\hline Apathy & $32(52.5)$ & $15(53.6)$ & $17(51.5)$ & 0.87 \\
\hline Disinhibition & $12(19.7)$ & $9(32.1)$ & $3(9.1)$ & 0.02 \\
\hline Motor disturbance & $3(5.0)$ & $2(7.1)$ & $1(3.1)$ & 0.59 \\
\hline Irritability & $29(47.5)$ & $16(57.1)$ & $13(39.4)$ & 0.17 \\
\hline Sleep disturbance & $16(26.2)$ & $9(32.1)$ & 7 (21.2) & 0.33 \\
\hline Appetite disturbance & 17 (27.9) & $9(32.1)$ & $8(24.2)$ & 0.49 \\
\hline Existence of severe depression & $2(3.3)$ & $1(3.6)$ & $1(3.0)$ & 0.90 \\
\hline ADL scoreb & $5.1 \pm 1.2$ & $4.9 \pm 1.3$ & $5.3 \pm 1.1$ & 0.18 \\
\hline Washing & $38(62.3)$ & $15(53.6)$ & $23(69.7)$ & 0.19 \\
\hline Dressing & $43(70.5)$ & $17(60.7)$ & $26(78.8)$ & 0.12 \\
\hline Toileting & $52(85.2)$ & $23(82.1)$ & $29(87.9)$ & 0.72 \\
\hline Transferring & $51(83.6)$ & $23(82.1)$ & $28(84.8)$ & 0.78 \\
\hline Continence & $40(65.6)$ & $18(64.3)$ & $22(66.7)$ & 0.84 \\
\hline Feeding & $55(90.2)$ & $24(85.7)$ & 31 (93.9) & 0.40 \\
\hline IADL scoreb & $1.9 \pm 1.3$ & $1.7 \pm 1.2$ & $2.1 \pm 1.4$ & 0.30 \\
\hline Ability to use telephone & $52(85.2)$ & $24(85.7)$ & $28(84.8)$ & 0.92 \\
\hline Ability to do shopping & $16(26.7)$ & $4(14.3)$ & $12(37.5)$ & 0.04 \\
\hline Ability to use transport & $32(52.5)$ & $14(50.0)$ & $18(54.6)$ & 0.72 \\
\hline Ability to manage own treatment & $16(26.2)$ & 5 (17.9) & $11(33.3)$ & 0.17 \\
\hline \multicolumn{5}{|l|}{ DQoLb } \\
\hline Self-esteem & $3.3 \pm 0.8$ & $3.4 \pm 0.7$ & $3.3 \pm 0.9$ & 0.68 \\
\hline Positive affect/humour & $3.6 \pm 0.7$ & $3.8 \pm 0.6$ & $3.5 \pm 0.8$ & 0.12 \\
\hline Negative affects & $2.3 \pm 0.6$ & $2.2 \pm 0.7$ & $2.4 \pm 0.6$ & 0.33 \\
\hline Feeling of belonging & $3.5 \pm 0.8$ & $3.7 \pm 0.8$ & $3.4 \pm 0.8$ & 0.22 \\
\hline Sense of aesthetics & $3.3 \pm 0.8$ & $3.4 \pm 0.8$ & $3.2 \pm 0.8$ & 0.55 \\
\hline \multicolumn{5}{|l|}{ Caregivers } \\
\hline Ageb & $66.6 \pm 14.4$ & $66.7 \pm 15.6$ & $67.5 \pm 13.5$ & 0.85 \\
\hline Male sex & $16(26.2)$ & $6(21.4)$ & $10(30.3)$ & 0.43 \\
\hline \multicolumn{5}{|l|}{ Immediate family caregiver (spouse or } \\
\hline child of patient) & $47(77.0)$ & $19(67.9)$ & $28(84.8)$ & 0.12 \\
\hline Presence of caregiver burden & $28(54.9)$ & $16(76.2)$ & $12(40.02)$ & 0.01 \\
\hline
\end{tabular}

RCD, rapid cognitive decline; MMSE, Mini Mental State Examination; NPI, Neuropsychiatric Inventory; ADL, Activities of Daily Living; IADL, Instrumental Activities of Daily Living; DQoL, Dementia Quality of Life.

a Data expressed as number (\%) unless otherwise indicated. b Data expressed as mean \pm standard deviation. c Body mass index $<21$. d Consumption of 4 or more medications. 
Barbe et al.: Predictive Factors of Rapid Cognitive Decline in Patients with Alzheimer Disease

Table 2. Multivariate analysis identifying factors associated with rapid cognitive decline at 12 months

\begin{tabular}{llc}
\hline & Odds ratio [95\% CI] & $p$ \\
\hline Immediate family caregiver (spouse or child of patient) & $0.27[0.26-0.28]$ & $<0.0001$ \\
Autonomy for washing (ADL) & $0.45[0.44-0.46]$ & $<0.0001$ \\
Polymedication & $0.61[0.60-0.62]$ & $<0.0001$ \\
Presence of caregiver burden & $3.50[3.40-3.60]$ & $<0.0001$ \\
\hline
\end{tabular}

Variables proposed in multivariate analysis were immediate family caregiver, autonomy for washing (ADL), polymedication, presence of caregiver burden, baseline MMSE score, the "positive affect/humour" domain of the Dementia Quality of Life, high school diploma or higher education, attending day care centre, disinhibition, irritability, autonomy for dressing (ADL), ability to do shopping and ability to manage own treatment (IADL). CI, confidence interval; ADL, Activities of Daily Living; IADL, Instrumental Activities of Daily Living.

remaining autonomy for washing and personal hygiene could help the patients to maintain their self-esteem, and in parallel, help to prevent cognitive decline. Conversely, when the patients' personal intimacy is affected and they have to accept help partially or totally to wash themselves, they can end up relinquishing this activity altogether, and in doing so, may also let go of other capacities, thus precipitating RCD. This is all the more relevant in our study, since the patients had mild to moderate dementia, and were therefore generally quite aware of what they could and could not do.

In our study, polymedication, defined as 4 or more drugs per day, was also shown to be a protective factor against RCD. This could be explained by better management of comorbidities that can mediate cognitive decline in $\mathrm{AD}$, such as diabetes or hypertension $[43,44]$. Indeed, these factors, and adequate control thereof, have previously been shown to be involved in the declining incidence of AD [45]. Although polymedication has often been accused of incurring a high risk of iatrogenic events [46], it could also be the reflection of better overall medical management.

The presence of caregiver burden as assessed by Zarit's scale was identified as a risk factor for RCD in our study. This relation has previously been illustrated in the SAFES cohort [16]. The informal help can have a positive impact, because it is in line with the image and the expected role of the caregiver. However, the duration of the caregiving situation, and the type of relationship that links the helper to the patient, or the presence of behavioural troubles in the patient can generate a burden on the caregiver. Zarit's scale makes it possible to evaluate the burden, in both material and emotional terms, that is created by the caregiving relation, and thus reflects the caregiver's suffering. Daily management of a patient with cognitive disorders has considerable repercussions on the caregiver, not only physically but also psychologically. The role of caregiver comes on top of the other roles the caregiver may have in life (as a spouse, a parent, at work, etc.). The role of caregiver may be taken on out of love or purely out of obligation, but either way, the role is generally taken on without any formal training. It can turn out to be physically and psychologically draining and can lead to social isolation, appearance of symptoms of depression, or exhaustion in the caregiver [47]. Caregiver burden has previously been shown to be a risk factor for institutionalization of the patient [48]. Furthermore, the presence of a significant burden can sometimes cause the exhausted caregiver to adopt inappropriate behaviour. For example, they may overstimulate the patient, pushing them beyond their capacities, and thereby generating behavioural disorders or depressive symptoms, and precipitating cognitive decline. Similarly, stimulation may be overly focused on one particular domain, such as autonomy, to the detriment of other 
Barbe et al.: Predictive Factors of Rapid Cognitive Decline in Patients with Alzheimer Disease

capacities, such as social interactions. A self-imposed mission as informal caregiver can also sometimes lead to the refusal of any other type of help, thereby depriving the patient of appropriate professional management adapted to the disease that could help to delay cognitive decline. Indeed, an interesting avenue of further research would be to investigate the impact of the caregiver's quality of life on the progression of the patient's disease.

Our study found no evidence supporting the hypothesis that better quality of life would protect against RCD, since no dimension of the DQoL scale was found to be associated with RCD. This is in line with a previous report by Kaufman et al. [49], who also failed to find an association between cognitive decline and quality of life as measured by the QoL-AD instrument. This lack of relation could be linked to the fact that the factors found to be associated with RCD in our study are also known to influence the quality of life of patients with AD [50].

Previous findings reporting that the level of education $[12,13]$, malnutrition $[9,16,17]$ and behavioural disorders $[12,18-20]$ were related to cognitive decline were not replicated in this study. The failure to observe any links between these factors and RCD could be due to the population of our study, which comprised patients with only mild to moderate AD, and not advanced disease. It could also be partially explained by the methodology used to evaluate cognitive decline. Indeed, cognitive decline is sometimes considered as a quantitative variable (number of MMSE points) and sometimes as a qualitative variable (RCD or no RCD).

One of the main difficulties in our study is the actual definition of RCD, as there does not exist a widely accepted consensus in this regard. Several studies have investigated the varying progression of dementia syndromes, searching in particular for factors associated with accelerated cognitive decline. However, the results of these studies are heterogeneous and discordant. This is likely due to the use of different definitions of RCD between reports. Some authors define RCD on the basis of MMSE score, as a loss of 5 points or more per year [5], a loss of 3 points or more in 6 months [51] or alternatively, a loss of 4 points or more in 6 months [9]. Others evaluate cognitive decline using other instruments such as the Alzheimer Disease Assessment Scale-cognitive component. In our study, we chose to define RCD as a loss of 3 or more points in 12 months, which is the threshold of loss of cognitive function known to be associated with an increase in mortality [52] and the average loss on the MMSE in subjects with untreated AD [53].

The small study population constitutes a limitation of our study. A lack of statistical power is possible due to this small population and other factors than those showing association with RCD in our study could be significant predictors of RCD. Moreover, included patients differed from excluded patients concerning baseline characteristics, which could represent a selection bias. However, the proportion of patients with RCD in our study (46\%) is in line with other reports (e.g. 46\% in O'Hara et al. [31], 47.9\% in Masse et al. [54] and $51.2 \%$ in Buccione et al. [55]). This argues in favour of the representativeness of our study sample. Furthermore, the results observed are also in line with previous reports.

In summary, our study underlines the importance of the patient-caregiver interaction in the progression of $\mathrm{AD}$. The nature of this relationship, and its potential deterioration through the existence of a caregiver burden, are factors that are known to influence behavioural disorders and institutionalization in AD patients. Our findings underscore the important impact of caregiver burden on RCD. These findings suggest that management and follow-up options for the patient should focus on therapeutic adjustment (of both medical and nonmedical therapies), as well as appropriate frequency of follow-up and coordination among health care providers, with appropriate attention being paid to the intensity of burden perceived by the caregiver. 


\section{Acknowledgements}

We would like to express our thanks to: Dr. Michèle Collart from Troyes general hospital, Troyes (France); Dr. Marie-Yvonne George from the Maison Hospitalière St Charles, Nancy (France); Dr. Charbanou Jochum from the University Hospital of Geneva (Switzerland); Dr. Annie Parent from Épernay general hospital, Épernay (France); Prof. Pierre Pfitzenmeyer (deceased) from the University Hospital of Dijon (France); Dr. Marie-Paule Poncelet-Gochard from Sedan general hospital, Sedan (France); Dr. Elisabeth Quignard from Sézanne general hospital, Sézanne (France); Dr. Étienne Ravenel from Joeuf general hospital, Joeuf (France); Dr. Olivier Rouaud from the University Hospital of Dijon (France); and Dr. Laure Vix from the general hospital of Charleville-Mézières (France) for their participation in collecting the data. We also thank Fiona Ecarnot (EA3920, University of Franche-Comté, Besançon, France) for translation and editorial assistance.

This study was supported by the French National Program for Clinical Research (PHRC 2004), the Mederic Alzheimer Foundation and the French National Institute of Health and Medical Research (INSERM).

\section{Disclosure Statement}

The authors declare no conflict of interest.

\section{References}

1 Cortes F, Nourhashemi F, Guerin O, Cantet C, Gillette-Guyonnet S, Andrieu S, Ousset JP, Vellas B; REAL-FR Group: Prognosis of Alzheimer's disease today: a two-year prospective study in 686 patients from the REAL-FR Study. Alzheimers Dement 2008;4:22-29.

-2 Aguero-Torres H, Fratiglioni L, Winblad B: Natural history of Alzheimer's disease and other dementias: review of the literature in the light of the findings from the Kungsholmen Project. Int J Geriatr Psychiatry 1998;13: 755-766.

-3 Schaufele M, Bickel H, Weyerer S: Which factors influence cognitive decline in older adults suffering from dementing disorders? Int J Geriatr Psychiatry 2002;17:1055-1063.

-4 Soto ME, Andrieu S, Arbus C, Ceccaldi M, Couratier P, Dantoine T, Dartigues JF, Gillette-Guyonette S, Nourhashémi F, Ousset JP, Poncet M, Portet F, Touchon J, Vellas B: Rapid cognitive decline in Alzheimer's disease. Consensus paper. J Nutr Health Aging 2008;12:703-713.

5 Doody RS, Massman P, Dunn JK: A method for estimating progression rates in Alzheimer disease. Arch Neurol 2001;58:449-454.

6 Capitani E, Cazzaniga R, Francescani A, Spinnler H: Cognitive deterioration in Alzheimer's disease: is the early course predictive of the later stages? Neurol Sci 2004;25:198-204.

7 Soto ME, Andrieu S, Cantet C, Reynish E, Ousset PJ, Arbus C, Gillette-Guyonnet S, Nourhashémi F, Vellas B; REAL-FR Group: Predictive value of rapid decline in Mini Mental State Examination in clinical practice for prognosis in Alzheimer's disease. Dement Geriatr Cogn Disord 2008;26:109-116.

-8 Hui JS, Wilson RS, Bennett DA, Bienias JL, Gilley DW, Evans DA: Rate of cognitive decline and mortality in Alzheimer's disease. Neurology 2003;61:1356-1361.

-9 Dumont C, Voisin T, Nourhashemi F, Andrieu S, Koning M, Vellas B: Predictive factors for rapid loss on the Mini-Mental State Examination in Alzheimer's disease. J Nutr Health Aging 2005;9:163-167.

10 Jacobs D, Sano M, Marder K, Bell K, Bylsma F, Lafleche G, Albert M, Brandt J, Stern Y: Age at onset of Alzheimer's disease: relation to pattern of cognitive dysfunction and rate of decline. Neurology 1994;44:1215-1220.

-11 Ho GJ, Hansen LA, Alford MF, Foster K, Salmon DP, Galasko D, Thal LJ, Masliah E: Age at onset is associated with disease severity in Lewy body variant and Alzheimer's disease. Neuroreport 2002;13:1825-1828.

12 Teri L, McCurry SM, Edland SD, Kukull WA, Larson EB: Cognitive decline in Alzheimer's disease: a longitudinal investigation of risk factors for accelerated decline. J Gerontol A Biol Sci Med Sci 1995;50A:M49-M55.

13 Stern Y, Albert S, Tang MX, Tsai WY: Rate of memory decline in AD is related to education and occupation: cognitive reserve? Neurology 1999;53:1942-1947.

14 Wilson RS, Li Y, Aggarwal NT, Barnes LL, McCann JJ, Gilley DW, Evans DA: Education and the course of cognitive decline in Alzheimer disease. Neurology 2004;63:1198-1202. 
15 Rasmusson DX, Carson KA, Brookmeyer R, Kawas C, Brandt J: Predicting rate of cognitive decline in probable Alzheimer's disease. Brain Cogn 1996;31:133-147.

16 Viatonou S, Drame M, Jolly D, Morrone I, Lang PO, Voisin T, Boyer DC, Schwebel G, Somme D, Blanchard F, Novella JL: Predictors of rapid cognitive decline among demented subjects aged 75 or more: ("Sujet Age Fragile-Evaluation et Suivi" Cohort-SAFES). Int J Geriatr Psychiatry 2009;24:709-715.

17 Ousset PJ, Nourhashemi F, Reynish E, Vellas B: Nutritional status is associated with disease progression in very mild Alzheimer disease. Alzheimer Dis Assoc Disord 2008;22:66-71.

18 Capitani E, Francescani A, Spinnler H: Are hallucinations and extrapyramidal signs associated with a steeper cognitive decline in degenerative dementia patients? Neurol Sci 2007;28:245-250.

19 Wilson RS, Tang Y, Aggarwal NT, Gilley DW, McCann JJ, Bienias JL, Evans DA: Hallucinations, cognitive decline, and death in Alzheimer's disease. Neuroepidemiology 2006;26:68-75.

20 Wilson RS, Gilley DW, Bennett DA, Beckett LA, Evans DA: Hallucinations, delusions, and cognitive decline in Alzheimer's disease. J Neurol Neurosurg Psychiatry 2000;69:172-177.

-21 Alonso J, Ferrer M, Gandek B, Ware JE Jr, Aaronson NK, Mosconi P, Rasmussen NK, Bullinger M, Fukuhara S, Kaasa S, Leplège A; IQQLA Project Group: Health-related quality of life associated with chronic conditions in eight countries: results from the International Quality of Life Assessment (IQOLA) Project. Qual Life Res 2004;13:283-298.

22 Michelson H, Bolund C, Brandberg Y: Multiple chronic health problems are negatively associated with health related quality of life (HRQoL) irrespective of age. Qual Life Res 2000;9:1093-1104.

23 Fan VS, Curtis JR, Tu SP, McDonell MB, Fihn SD; Ambulatory Care Quality Improvement Project Investigators: Using quality of life to predict hospitalization and mortality in patients with obstructive lung diseases. Chest 2002;122:429-436.

24 Kanwal F, Gralnek IM, Hays RD, Zeringue A, Durazo F, Han SB, Saab B, Bolus R, Spiegel BM: Health-related quality of life predicts mortality in patients with advanced chronic liver disease. Clin Gastroenterol Hepatol 2009;7:793-799.

25 Fan VS, Au DH, McDonell MB, Fihn SD: Intraindividual change in SF-36 in ambulatory clinic primary care patients predicted mortality and hospitalizations. J Clin Epidemiol 2004;57:277-283.

-26 Dominick KL, Ahern FM, Gold CH, Heller DA: Relationship of health-related quality of life to health care utilization and mortality among older adults. Aging Clin Exp Res 2002;14:499-508.

27 American Psychiatric Association: Diagnostic and Statistical Manual of Mental Disorders, ed 4, text revised (DSM-IV TR). Washington, American Psychiatric Association, 2000.

-28 McKhann G, Drachman D, Folstein M, Katzman R, Price D, Stadlan EM: Clinical diagnosis of Alzheimer's disease: report of the NINCDS-ADRDA Work Group under the auspices of Department of Health and Human Services Task Force on Alzheimer's Disease. Neurology 1984;34:939-944.

-29 Folstein MF, Folstein SE, McHugh PR: "Mini-mental state". A practical method for grading the cognitive state of patients for the clinician. J Psychiatr Res 1975;12:189-198.

30 National Institute for Health and Care Excellence: Donepezil, galantamine, rivastigmine and memantine for the treatment of Alzheimer's disease. Technology appraisal guidance [TA217]. 2011. https://www.nice.org. uk/guidance/TA217.

-31 O’Hara R, Thompson JM, Kraemer HC, Fenn C, Taylor JL, Ross L, Yesavage JA, Bailey AM, Tinklenberg JR: Which Alzheimer patients are at risk for rapid cognitive decline? J Geriatr Psychiatry Neurol 2002;15:233-238.

32 Wimo A, Jonsson L, Zbrozek A: The Resource Utilization in Dementia (RUD) instrument is valid for assessing informal care time in community-living patients with dementia. J Nutr Health Aging 2010;14:685-690.

33 Zarit SH, Reever KE, Bach-Peterson J: Relatives of the impaired elderly: correlates of feelings of burden. Gerontologist 1980;20:649-655.

34 Sundararajan V, Henderson T, Perry C, Muggivan A, Quan H, Ghali WA: New ICD-10 version of the Charlson comorbidity index predicted in-hospital mortality. J Clin Epidemiol 2004;57:1288-1294.

35 Haute Autorité de Santé: Stratégie de prise en charge en cas de dénutrition protéino-énergétique chez la personne agée. 2007. http://www.has-sante.fr/portail/upload/docs/application/pdf/synthese_denutrition_ personnes_agees.pdf.

-36 Cummings JL, Mega M, Gray K, Rosenberg-Thompson S, Carusi DA, Gornbein J: The Neuropsychiatric Inventory: comprehensive assessment of psychopathology in dementia. Neurology 1994;44:2308-2314.

-37 Alexopoulos GS, Abrams RC, Young RC, Shamoian CA: Cornell Scale for Depression in Dementia. Biol Psychiatry 1988;23:271-284.

-38 Katz S, Ford AB, Moskowitz RW, Jackson BA, Jaffe MW: Studies of illness in the aged. The index of ADL: a standardized measure of biological and psychosocial function. JAMA 1963;185:914-919.

-39 Barberger-Gateau P, Commenges D, Gagnon M, Letenneur L, Sauvel C, Dartigues JF: Instrumental activities of daily living as a screening tool for cognitive impairment and dementia in elderly community dwellers. J Am Geriatr Soc 1992;40:1129-1134.

40 Brod M, Stewart AL, Sands L, Walton P: Conceptualization and measurement of quality of life in dementia: the dementia quality of life instrument (DQoL). Gerontologist 1999;39:25-35.

-41 Efron B: The Jackknife, the Bootstrap, and Other Resampling Plans. CBMS-NSF. Philadelphia, SIAM, 1982.

42 Rossi AS, Rossi PH: Of Human Bonding: Parent-Child Relations across the Life Course. New York, Walter de Gruyter \& Co, 1990. 
43 Sanz CM, Hanaire H, Vellas BJ, Sinclair AJ, Andrieu S, Group RFS: Diabetes mellitus as a modulator of functional impairment and decline in Alzheimer's disease. The Real.FR cohort. Diabet Med 2012;29:541-548.

44 Shah K, Qureshi SU, Johnson M, Parikh N, Schulz PE, Kunik ME: Does use of antihypertensive drugs affect the incidence or progression of dementia? A systematic review. Am J Geriatr Pharmacother 2009;7:250-261.

-45 Schrijvers EM, Verhaaren BF, Koudstaal PJ, Hofman A, Ikram MA, Breteler MM: Is dementia incidence declining?: trends in dementia incidence since 1990 in the Rotterdam Study. Neurology 2012;78:1456-1463.

-46 Onder G, Petrovic M, Tangiisuran B, Meinardi MC, Markito-Notenboom WP, Somers A, Rajkumar C, Bernabei $\mathrm{R}$, van der Cammen TJ: Development and validation of a score to assess risk of adverse drug reactions among in-hospital patients 65 years or older: the GerontoNet ADR risk score. Arch Intern Med 2010;170:1142-1148.

-47 Wolff JL, Spillman BC, Freedman VA, Kasper JD: A national profile of family and unpaid caregivers who assist older adults with health care activities. JAMA Intern Med 2016;176:372-379.

-48 Sansoni J, Anderson KH, Varona LM, Varela G: Caregivers of Alzheimer's patients and factors influencing institutionalization of loved ones: some considerations on existing literature. Ann Ig 2013;25:235-246.

-49 Kaufman Y, Anaki D, Binns M, Freedman M: Cognitive decline in Alzheimer disease: impact of spirituality, religiosity, and QOL. Neurology 2007;68:1509-1514.

50 Barbe C, Morrone I, Wolak-Thierry A, Drame M, Jolly D, Novella JL, Mahmoudi R: Impact of functional alterations on quality of life in patients with Alzheimer's disease. Aging Ment Health 2016:1-6.

51 Dumont C, Gillette-Guyonnet S, Andrieu S, Cantet C, Ousset PJ, Vellas B: Rapid loss of the Mini Mental State Examination: REAL.FR study. Rev Med Interne 2003;24(suppl 3):345s-350s.

52 Carcaillon L, Peres K, Pere JJ, Helmer C, Orgogozo JM, Dartigues JF: Fast cognitive decline at the time of dementia diagnosis: a major prognostic factor for survival in the community. Dement Geriatr Cogn Disord 2007;23:439-445.

53 Morris JC, Edland S, Clark C, Galasko D, Koss E, Mohs R, van Belle G, Fillenbaum G, Heyman A: The consortium to establish a registry for Alzheimer's disease (CERAD). Part IV. Rates of cognitive change in the longitudinal assessment of probable Alzheimer's disease. Neurology 1993;43:2457-2465.

54 Masse I, Bordet R, Deplanque D, Al Khedr A, Richard F, Libersa C, Pasquier F: Lipid lowering agents are associated with a slower cognitive decline in Alzheimer's disease. J Neurol Neurosurg Psychiatry 2005;76:16241629.

55 Buccione I, Perri R, Carlesimo GA, Fadda L, Serra L, Scalmana S, Caltagirone C: Cognitive and behavioural predictors of progression rates in Alzheimer's disease. Eur J Neurol 2007;14:440-446. 